\title{
Integration of leadership training into a problem/ case-based learning program for first- and second-year medical students
}

This article was published in the following Dove Press journal:

Advances in Medical Education and Practice

\author{
Samara B Ginzburg \\ Susan Deutsch \\ Jaclyn Bellissimo \\ David E Elkowitz \\ Joel NH Stern \\ Robert Lucito
}

Department of Science Education, Zucker School of Medicine at Hofstra/ Northwell, Hempstead, NY, USA
Correspondence: Samara B Ginzburg Department of Science Education, Zucker School of Medicine at Hofstra/Northwell, 500 Hofstra University, Hempstead, NY II 549 , USA

Tel +I $5|6463750|$

$\mathrm{Fax}+|516463563|$

Email samara.ginzburg@hofstra.edu
Purpose: The evolution of health care systems in response to societal and financial pressures has changed care delivery models, which presents new challenges for physicians. Leadership training is increasingly being recognized as an essential component of medical education training to prepare physicians to meet these needs. Unfortunately, most medical schools do not include leadership training. It has been suggested that a longitudinal and integrated approach to leadership training should be sought. We hypothesized that integration of leadership training into our hybrid problem-based learning (PBL)/case-based learning (CBL) program, Patient-Centered Explorations in Active Reasoning, Learning and Synthesis (PEARLS), would be an effective way for medical students to develop leadership skills without the addition of curricular time.

Methods: We designed a unique leadership program in PEARLS in which 98 medical students participated during each of their six courses throughout the first 2 years of school. A program director and trained faculty facilitators educated students and coached them on leadership development throughout this time. Students were assessed by their facilitator at the end of every course on development of leadership skills related to teamwork, meaningful self-assessment, process improvement, and thinking outside the box.

Results: Students consistently improved their performance from the first to the final course in all four leadership parameters evaluated. The skills that demonstrated the greatest change were those pertaining to thinking outside the box and process improvement.

Conclusion: Incorporation of a longitudinal and integrated approach to leadership training into an existing PBL/CBL program is an effective way for medical students to improve their leadership skills without the addition of curricular time. These results offer a new, time-efficient option for leadership development in schools with existing PBL/CBL programs.

Keywords: student-centered, learner-centered, self-directed learning, curricular innovation, higher-order thinking

\section{Introduction}

The evolution of health care systems in response to financial and societal pressures presents new challenges for physicians, necessitating changes in training to enable physicians to meet these challenges. These include changes to health care financing with an increased number and complexity of regulations, which are driving changes in health care delivery models. ${ }^{1-3}$ As a result, there has been a shift in how and by whom care is delivered. Previously, doctors primarily functioned autonomously. However, the current structure of health care relies much more on collaborative care models, and physicians must be able to lead and work in health care teams to provide highquality, cost-effective patient care..$^{3-6}$ Therefore, it is critical for physicians, and those 
in training to become physicians, to develop and hone their leadership and teamwork skills. ${ }^{2,4-6}$

The increasing importance of leadership training for physicians has been recognized by those at the forefront of medicine.$^{3,5,7}$ Specifically, the need to improve such training has been addressed by several of the advisory groups on health care and health education including the Institute of Medicine and the Association of American Medical Colleges. These groups contend that it is necessary to develop physicians as leaders who can envision the future of health care, have the skills needed to effectuate change, and can manage the teams and systems that will improve health care. ${ }^{1,6}$

A number of approaches are being taken to increase leadership training in both graduate medical education (GME) and undergraduate medical education (UME). GME training programs include workshops and intermittent as well as longitudinal programming that incorporate leadership training. ${ }^{8}$ However, with a larger number of patients being followed by resident teams and restricted duty hours, the time available to dedicate to developing skills beyond direct clinical care, such as those related to leadership, has decreased. ${ }^{9}$ Leadership development during UME has been introduced in various ways including classroom activities, simulation exercises, and integration into clinical experiences. These initiatives vary from individual experiences to longitudinal programs. ${ }^{3}$ Challenges in UME faced by those working in this area include finding curricular time and appropriately trained faculty. A recent systematic review of leadership programs in UME curricula concluded that a longitudinal and integrated approach to leadership training should be sought and suggested this as an area for future innovation and study. ${ }^{3}$

The Zucker School of Medicine at Hofstra/Northwell (ZSOM) was established 7 years ago. As part of our educational program from the inception, we chose to create a longitudinal leadership development program for first- and second-year medical students. We hypothesized that integration of leadership training into our hybrid problem-based learning (PBL)/case-based learning (CBL) program would be an effective methodology to develop leadership skills in these students, while they were contemporaneously learning the fundamental basic sciences via PBL/CBL. Importantly, this strategy did not require the addition of curricular time.

\section{Methods \\ PBL/CBL pedagogy}

This longitudinal study took place during the 2015-2016 and 2016-2017 academic years and followed one cohort of students throughout their first and second years of medical school. During this time, students were enrolled in six required, integrated, sequential courses (Courses 1 through 6). Each week, content within a course focused on a curricular theme and was anchored in our small group, PBL/ CBL program, Patient-Centered Explorations in Active Reasoning, Learning and Synthesis (PEARLS). PEARLS cases prompted students to develop biomedical, clinical, and social science learning objectives (LOs). Each student was assigned to a PEARLS group of eight or nine peers and one faculty facilitator for the duration of the course (11 weeks). Students participated in three 2-hour PEARLS sessions per week. The first session was dedicated to students dissecting two cases and developing specific biomedical science LOs; the second and third sessions of the week were devoted to students' discussion and synthesis of the material. Students' discussions during these second and third sessions each week primarily focused on the basic sciences and relating that content to clinical and social science topics raised in the cases. Student groups changed for each of the six courses. Development of leadership skills was integrated into the PEARLS program during this time via three routes: the PEARLS' director role, the PEARLS' faculty facilitator role, and the student role.

\section{Programmatic/PEARLS' director role}

At the start of Course 1, all students received the PEARLS student manual created by the PEARLS' directors. The manual defined student expectations for leadership skills relating to four areas: promoting teamwork through listening to and considering suggestions from teammates, developing skills of self-reflection by regularly performing and sharing thoughtful self-assessments, developing skills utilized in process improvement, and challenging group members to "think outside the box" via the development of higher order application questions, called triggers, that students present to their groups. The manual also explained that students would be assessed in each of these leadership skills at the end of each course through the Faculty Assessment of Student (FAS) form (Table 1), a copy of which was included in the manual. A total of 11 of the 22 questions on the FAS form pertained to leadership, and the FAS was used to assess students for all six courses.

Large group informational sessions led by the PEARLS' directors for all students and facilitators participating in a course were called PEARLS Go! sessions. There were a total of five PEARLS Go! sessions held during the study period, one session in each of Courses 1, 2, 3, 4, and 5, in which leadership coaching of the students by the PEARLS Directors' 
took place. These sessions began with the PEARLS' directors "going" with any questions the students had related to the program and then discussing and answering them. The PEARLS' directors then coached the students on programmatic expectations related to leadership that were developmentally appropriate for the course in which students were enrolled (Table 2).

\section{PEARLS' faculty facilitator role}

All faculty (physician and $\mathrm{PhD}$ educators) participated in faculty development prior to assuming the role of facilitator. Faculty development consisted of, 1) a minimum of six sessions of direct observation of PEARLS sessions with experienced facilitators followed by multiple debriefing meetings; 2) reading of the PEARLS student and facilitator manuals; 3) reading "Problem-Based Learning: An Approach to Medical Education"10; and 4) participating in a 2-hour faculty development session dedicated to understanding the rationale behind the leadership expectations of students and how best to develop their leadership skills. Once serving as facilitators, all attended weekly faculty development sessions, led by the PEARLS' directors, during the courses they were facilitating. During these sessions, the PEARLS' directors discussed how best to facilitate development of leadership skills in students, facilitators shared specific examples from their groups of which methods they were trying and discussed what worked and what did not work, and the PEARLS' directors advised them on how to address any challenges they encountered. In addition, each time a FAS form was to be distributed for completion, one session was dedicated to calibrating facilitator scoring.

During PEARLS sessions, facilitators cultivated the leadership expectations with students through "wrap-up" discussions, which were 25-30-minute discussions that took place at the conclusion of each PEARLS session. Wrap-up time was dedicated to self-reflection and process improvement, and during this time, facilitators posed wrap-up questions to students that required them to consider different topics relevant to becoming physicians, including leadership, which the group then discussed. The FAS form was used to document students' leadership skills by their facilitator twice during every course, once at midcourse, which was formative, and again at the end of course, which served as a summative assessment. The same questions were on the FAS form for both mid and end of course assessments. Facilitators met with each student one-on-one during the midpoint of every course to discuss the student's development of leadership skills assessed on the FAS form.

Table I Faculty Assessment of Student (FAS) questions related to leadership

\section{Teamwork}

I. Listens attentively and considers alternative explanations and suggestions provided by other teammates

2. Every time when serving as leader, demonstrates the ability to manage the team and coordinate the activities of team members

Performing self-assessment

3. During Monday check-in, performs self-assessment of learning from prior week

4. During wrap-up, performs specific, constructive self-assessment

Process improvement

5. During wrap-up provides an analysis of the group's (system's) processes

6. Creates and comments upon a personal action plan from week to week

7. Modifies behavior based upon areas identified during self-assessment, group feedback, and mid-course meeting

Thinking outside the box

8. Successfully creates triggers for discussion by the group

9. Presents triggers to the group

10. Develops clearly stated question/s for the group as part of triggers

I I. Effectively facilitates discussion of triggers that lead to higher order conversations

Table 2 Content of Patient-Centered Explorations in Active Reasoning, Learning and Synthesis (PEARLS) Go! sessions related to leadership

\begin{tabular}{lll}
\hline Course & MSI/MS2 & Discussion topics \\
\hline I & MSI & Defining programmatic expectations related to leadership \\
2 & CSI & $\begin{array}{l}\text { Coaching related to how to create triggers, the relationship between learning to think outside the box and } \\
\text { leadership, developing and following up on action plans }\end{array}$ \\
3 & MSI & Questions answered related to triggers and leadership \\
4 & MSI & Questions answered related to triggers and leadership \\
5 & MS2 & Coaching related to thinking broadly and the dangers of premature closure related to leadership
\end{tabular}

Notes: MSI, first year medical student; MS2, second year medical student. 


\section{Student role}

A total of 98 students participated in this study. During the first meeting of all PEARLS groups prior to the start of Course 1 , facilitators reviewed the leadership expectations from the student manual with the students and the group discussed these expectations and any questions they had. Each of the students had the opportunity to lead two or three PEARLS sessions per course on a rotating schedule (with the exception of the shortest course, Course 1, in which the majority of students were leader once). The session leader was responsible for setting the agenda with the group at the start of each session, refocusing the group if the discussion got off track, encouraging participation from all group members, and periodically ensuring the group had synthesized the material. All students (beginning in Course 2), were responsible for creating, presenting, and facilitating their triggers each week, even when they were not the designated leader.

At the start of the first session each week, all students participated in a brief self-assessment exercise in which they reflected upon their consolidation of the material from the prior week and identified any significant remaining learning issues. At the conclusion of each PEARLS session, at the end of the wrap-up discussion, all students were expected to perform self and group assessments, provide suggestions for improvement, intermittently develop and follow up on action plans (beginning with Course 2), and answer the wrap-up question posed by the facilitator.

\section{Ethics}

This study was submitted to Hofstra University's institutional review board and was determined to be exempt from review. All data utilized for this study came from students who gave their written informed consent after reading and agreeing to the following statement, 'I voluntarily consent to participate in the Research Registry and therefore give permission for the educational data that has been or will be collected throughout my undergraduate experience at Hofstra Northwell School of Medicine to be included in the Registry'.

\section{Results}

\section{Longitudinal cohort analysis}

We analyzed the results of students' performance on the summative end of course FAS form for each of the six courses. Each question on the FAS has three to five possible anchors on a Likert scale with the lowest value being the most undesirable and the highest value the most desirable. Figure 1 displays the results of the average of all evaluations for each leadership question that were normalized by dividing by the number of possible responses for the specific question to convert all averages to a $0-1$ scale for Courses 1,2 , and 6 .

The skills that demonstrated the greatest change from Course 1 to Course 6 were those pertaining to creative thinking or "thinking outside the box" (FAS questions 9, 10, and 11) and process improvement (FAS question 6). These were skills that students were not expected to begin to develop until Course 2 .

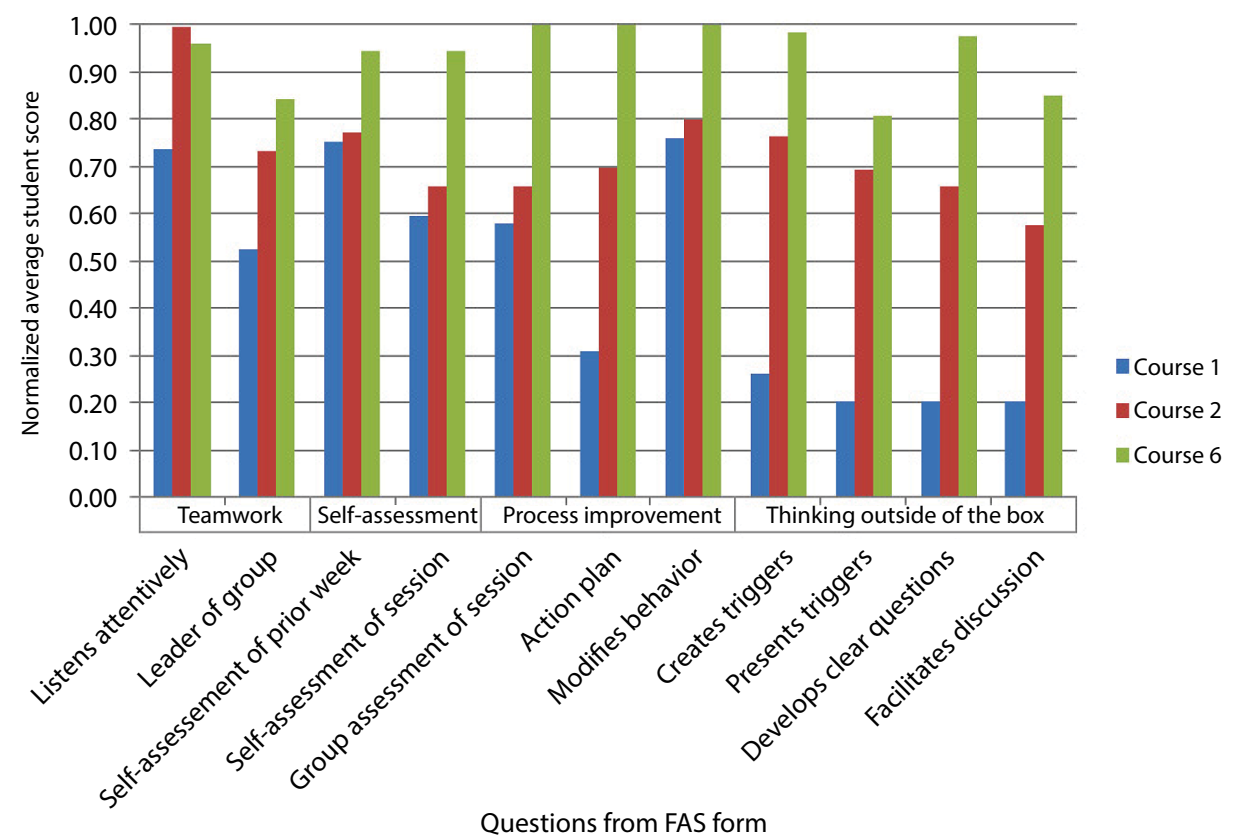

Figure I Normalized average values for students' scores on the Faculty Assessment of Student (FAS) form for leadership questions progressing through three courses. 
The baseline for questions on skills the students were not expected to begin to develop until Course 2 (FAS questions 6 , $8,9,10$, and 11) was not 0.0 because some students already had and demonstrated these skills. Students consistently improved their performance from Course 1 to Course 6 in performing self-assessments (FAS questions 3 and 4), process improvement (FAS questions 5, 6, and 7), and thinking outside the box (FAS questions 8, 9, 10, and 11).

For one of the skills related to teamwork (FAS question 1), student performance improved from Course 1 to Course 2 but decreased by the end of Course 6 . However, the change was only 0.06 on our 4-point scale (from 3.90 to 3.84), which was insignificant.

All students achieved the highest expectation for three questions that assessed skills in process improvement (FAS questions 6,7 , and 8) by the end of Course 6 .

\section{Discussion}

A total of $70 \%$ of US medical schools use PBL at least to some extent during the preclerkship years. ${ }^{6}$ As time is scarce in medical curricula, we experimented with integrating leadership training into our PBL/CBL program.

We utilized the FAS form for all six courses. This allowed us to track the development of specific leadership skills in individual students. Students in our program were able to develop effective leadership skills in teamwork, performing self-assessments, process improvement, and thinking outside the box during their first and second years of medical school. These particular leadership skills were selected for inclusion in our study because they have been recognized as important for physician leaders ${ }^{3,6}$ and naturally lend themselves to incorporation into a $\mathrm{PBL} / \mathrm{CBL}$ program. Our students' development of these skills is significant because most prior studies of leadership training in UME have not demonstrated changes in students' behaviors. ${ }^{3}$

The area in which our students achieved the highest skill level was process improvement. Among the leadership skills that they developed, this is a skill of critical importance for physician leaders in order to improve the delivery of highquality health care. ${ }^{11}$ Most importantly, integration of leadership training skills into our PEARLS program was achieved without negatively impacting students' learning of the fundamental basic sciences as assessed by the United States Medical Licensing Examination (USMLE) Step 1 scores; class mean was above the national mean for the cohort that completed this study, which is similar to the classes that preceded them.

Our study has several limitations. We recognize that there were not a standard number of leadership wrap-up questions and as a result, some students may have participated in more wrap-up discussions related to leadership than others. To attempt to mitigate this, students changed facilitators every course and were not paired with a facilitator they previously had. Going forward, we plan to have all facilitators pose at least two wrap-up questions per course dedicated to discussing leadership. Another limitation is the fact that the FAS form is a tool we created and has not yet been validated. Although our results are promising, we will next utilize external instruments to assess leadership traits and skills to better understand their development in our students while we work toward validation of the FAS form. In addition, we will explore ways of integrating leadership components of this program into existing educational sessions during clerkships for third-year students.

\section{Conclusion}

First- and second-year medical students at ZSOM were able to effectively improve their leadership skills through a longitudinal leadership program that was integrated into a $\mathrm{PBL} / \mathrm{CBL}$ program, which did not add extra time into the curriculum or adversely affect their acquisition of basic science knowledge as assessed by USMLE Step 1. We will continue to follow this cohort during their third-year clinical rotations to study the impact of this leadership program on their performance and will utilize external tools to measure leadership skills and traits in our new first- and second-year students as we seek to validate our FAS form.

\section{Acknowledgments}

The authors would like to acknowledge Saori W. Herman, MLIS, and Krista Paxton for their assistance with preparation of the manuscript. The authors would like to acknowledge Joanne M. Willey, PhD, for her critical comments on the manuscript as well as the contributions of the faculty, staff, and students at the Zucker School of Medicine at Hofstra/Northwell who made the work described here possible.

\section{Disclosure}

The authors report no conflicts of interest in this work.

\section{References}

1. Clyne B, Rapoza B, George P. Leadership in undergraduate medical education: training future physician leaders. $R$ I Med J (2013) 2015;98(9):36-40.

2. Smith KL, Petersen DJ, Soriano R, Friedman E, Bensinger LD. Training tomorrow's teachers today: a national medical student teaching and leadership retreat. Med Teach. 2007;29(4):328-334. 
3. Webb AM, Tsipis NE, McClellan TR, et al. A first step toward understanding best practices in leadership training in undergraduate medical education: a systematic review. Acad Med. 2014;89(11):1563-1570.

4. Rosenman ED, Shandro JR, Ilgen JS, Harper AL, Fernandez R. Leadership training in health care action teams: a systematic review. Acad Med. 2014;89(9):1295-1306.

5. Stoller JK. Commentary: recommendations and remaining questions for health care leadership training programs. Acad Med. 2013;88(1):12-15.

6. Varkey P, Peloquin J, Reed D, Lindor K, Harris I. Leadership curriculum in undergraduate medical education: a study of student and faculty perspectives. Med Teach. 2009;31(3):244-250.
7. Institute of Medicine. Academic Health Centers: Leading Change in the 21st Century. Washington, DC: National Academy Press; 2004.

8. Frich JC, Brewster AL, Cherlin EJ, Bradley EH. Leadership development programs for physicians: a systematic review. J Gen Intern Med. 2015;30(5):656-674.

9. Lund KJ, Teal SB, Alvero R. Resident job satisfaction: one year of duty hours. Am J Obstet Gynecol. 2005;193(5):1823-1826.

10. Barrows HS, Tamblyn RM. Problem-Based Learning: An Approach to Medical Education. New York: Springer Publishing Co; 1980.

11. Institute of Medicine. Crossing the Quality Chasm: A New Health System for the 21st Century. Washington, DC: National Academy Press; 2001.

\section{Publish your work in this journal}

Advances in Medical Education and Practice is an international, peerreviewed, open access journal that aims to present and publish research on Medical Education covering medical, dental, nursing and allied health care professional education. The journal covers undergraduate education, postgraduate training and continuing medical education including emerging trends and innovative models linking education, research, and health care services. The manuscript management system is completely online and includes a very quick and fair peer-review system. Visit http://www.dovepress.com/testimonials.php to read real quotes from published authors.

Submit your manuscript here: http://www.dovepress.com/advances-in-medical-education-and-practice-journal 